Nordisk Tidsskrift for Kriminalvidenskab 2003

\title{
BROTT OCH STRAFF I SKANDINAVIEN. EN ÖVERBLICK*
}

\section{AV PROFESSOR, JUR. DR. HANNS VON HOFER}

This short overview of available statistical data on crime and penal systems in Scandinavia indicates that the level of traditional forms of crime in Scandinavia is on par with or lower than that found in many other European countries. The extent of drug abuse also appears to lie either at or below the European average. As elsewhere in Western Europe, Scandinavia experienced a substantial increase in crime rates during the post-war period - indicating that these recorded increases may have common structural roots. The 1990s witnessed a stabilization of theft rates, albeit on a high level. Increasing equality between women and men may have contributed to an increase in the reporting of violent and sexual offences against women (and children), making these offences more visible. The system of formal control in the Scandinavian countries is characterised by relatively low police density, a falling clear-up rate, the imposition of fines in a high proportion of criminal cases, and relatively low prison populations. The paper finishes with a summary of basic similarities in regard to crime policies within the Scandinavian countries. ${ }^{* *}$

Komparativ välfärdsforskning har visat ett ganska tydligt mönster för hur olika länder inom Europeiska unionen (inkl. Norge) placerar sig med avseende på den materiella levnadsstandarden och utformningen av välfärdssystemen. Europeiska unionen kan indelas i tre mer eller mindre homogena grupper (Vogel, 1997):

- en nordeuropeisk grupp (Danmark, Finland, Norge och Sverige) vilken visar höga nivåer när det gäller sociala utgifter och deltagande i arbetsmarknaden samt svaga familjeband. Beträffande inkomstfördelning karaktäriseras gruppen av relativt låga inkomst- och klasskillnader och begränsad fattigdom, men av en hög nivå av ojämlikhet mellan de yngre och de äldre generationerna;

\footnotetext{
* Artiklen har utarbetats tillsammans med Britta Kyvsgaard, Tapio Lappi-Seppälä och Paul Larsson.

** Title in English: Crime and Punishment in Scandinavia. An Overview. Original in Swedish.
} 
- en sydeuropeisk grupp (Grekland, Italien, Portugal och Spanien) som karaktäriseras av en mycket lägre nivå av välfärd, en lägre grad av sysselsättning men starka familjetraditioner. Här finner vi högre inkomstoch klasskillnader och fattigdom, men låga nivåer av ojämlikhet mellan generationerna;

- en västeuropeisk grupp i en mellanposition (Österrike, Belgien, Frankrike, Tyskland, Irland, Luxemburg, Nederländerna och Storbritannien). Storbritannien gränsar emellertid till den sydeuropeiska gruppen när det gäller dess höga nivåer av inkomstskillnader, fattigdom och ojämlikhet.

Mot denna bakgrund följer här en tämligen enkel beskrivning av den traditionella' brottsligheten (dvs. stöld och våld) i de skandinaviska länderna. Resultaten sätts i ett europeiskt perspektiv för att belysa frågan om de skilda välfärdsmönstren motsvaras av skillnader när det gäller brott och straff.

\section{Internationella brottsofferundersökningar (International Crime Victims Surveys, ICVS)}

Beroende på de stora variationerna i hur vanlig brottsstatistik insamlas och presenteras i olika länder, är det allmänt accepterat att jämförelser av brottsnivåer inte bör baseras på jämförelser av nationell brottsstatistik. I detta sammanhang är det bättre att använda sig av de internationella brottsofferundersökningarna som finns tillgängliga sedan slutet av 1980-talet (van Kesteren, Mayhew \& Nieuwbeerta, 2000), även om också dessa datainsamlingar inte är fria från metodproblem. Exempelvis förekommer delvis höga svarsbortfall och kulturella skillnader och detta kan försvåra svarens jämförbarhet mellan länderna.

De internationella offerundersökningarna genomförs med hjälp av standardiserade frågor och telefonintervjuer som baseras på slumpmässiga urval på mellan 1000 och 5000 personer från respektive land. Totalt har nitton europeiska länder deltagit i fyra undersökningar (1989, 1992, 1996 och 2000), varav Finland är det enda skandinaviska land som deltagit i samtliga fyra; Sverige i tre; samt Norge och Danmark i vardera en undersökning. Brottskategorierna som ingår i undersökningen är bilstöld, motorcykelstöld, cykelstöld, inbrott och inbrottsförsök, rån, stöld från person, sexuella övergrepp samt misshandel/hot.

Resultaten från samtliga undersökningar mellan 1989 och 2000, oavsett hur många gånger de enskilda länderna deltagit, har summerats i tabellen nedan. 
Tabell 1. Andel (procent) personer utsatta för olika brottstyper, 1989, 1992, 1996 och 2000, enligt International Crime Victims Survey (ICVS).

\begin{tabular}{lccccc}
\hline & DK & FI & NO & SE & EUR9 \\
& 2000 & $1989-2000$ & 1989 & $1992-2000$ & $1989-2000$ \\
& & & & & \\
Bilstöld & 1,1 & 0,5 & 1,1 & 1,4 & 1,1 \\
Stöld från bil & 3,4 & 2,9 & 2,8 & 4,7 & 4,8 \\
Skadegörelse av bil & 3,8 & 4,4 & 4,6 & 4,6 & 7,5 \\
Mc stöld & 0,7 & 0,2 & 0,3 & 0,5 & 0,6 \\
Cykelstöld & 6,7 & 4,5 & 2,8 & 7,7 & 3,4 \\
Inbrott & 3,1 & 0,5 & 0,8 & 1,5 & 1,8 \\
Inbrottsförsök & 1,5 & 0,7 & 0,4 & 0,9 & 1,8 \\
Rån & 0,7 & 0,7 & 0,5 & 0,6 & 1,0 \\
Stöld från person & 4,2 & 3,6 & 3,2 & 4,9 & 4,1 \\
Sexuella övergrepp & 2,5 & 2,6 & 2,2 & 2,1 & 2,2 \\
Misshandel och hot & 3,6 & 3,9 & 3,0 & 3,7 & 2,7 \\
Samtliga 11 brottstyper & 23,0 & 18,8 & 16,4 & 23,4 & 22,7 \\
& & & & & \\
Antal utförda intervjuer & 3.007 & 8.327 & 1.009 & 4.707 & 44.396 \\
Svarsfrekvens & $66 \%$ & $82 \%$ & $71 \%$ & $72 \%$ & $50 \%$ \\
\hline
\end{tabular}

DK (Danmark): 2000 endast; FI (Finland): 1989, 1992, 1996, 2000; NO (Norge): 1989 endast; SE (Sverige): 1992, 1996, 2000; EUR9: Österrike, Belgien, England \& Wales, Frankrike, (Väst)Tyskland, Italien, Nederländerna, Spanien/Katalonien och Schweiz.

Generellt sett tycks utsattheten för brott vara lägre i Finland och Norge än i Sverige och Danmark (dock har Norge endast deltagit $1989^{2}$ och Danmark endast 2000). I de flesta fall ligger Sverige nära det europeiska genomsnittet. Liknande skillnader mellan de skandinaviska länderna fanns även under 1980-talet när jämförelser gjordes mellan nationella brottsofferundersökningar i de enskilda länderna. Vid denna tidpunkt var de danska resultaten på många områden snarlika de resultat som visades i Sverige (RSÅ, 1990:146 ff). Danmark och Sverige utmärker sig (tillsammans med Nederländerna) genom höga nivåer av cykelstölder, medan alla skandinaviska länder på det hela uppvisar relativt låga nivåer av skadegörelse på bilar och rån. Dock noteras i de skandinaviska länderna något högre nivåer av misshandel och hot. Det har spekulerats om detta delvis kan förklaras genom att kvinnor i Skandinavien kännetecknas av en högre grad av medvetenhet och på samma gång lägre tolerans när det gäller vad de anser som socialt acceptabelt i samband med hot och våld (HEUNI, 1998:132f; 163, $349,432)$. 
Data från dödsorsaksstatistiken (European Sourcebook, 2003) pekar på att nivån av dödligt våld i Danmark, Norge och Sverige är ungefär densamma jämfört med den som rapporteras i Västeuropa (omkring 1,2 per 100000 invånare), medan Finland fortfarande uppvisar betydligt högre frekvenser (ungefär 3,0 per 100000 invånare; Lappi-Seppäla, 2001).

En annan markant skillnad mellan de skandinaviska länderna är den höga rapporterade frekvensen av inbrott i Danmark. Jämförelser med data i brottsstatistiken ger vid handen att bostadsinbrott faktiskt skulle kunna vara högre i Danmark jämfört med Finland, Norge och Sverige.

En tredje påfallande avvikelse är den låga uppgivna risken för bilstöld i Finland. Risker på 0,4 procent uppmättes i tre av fyra undersökningar. Enbart under året 1992 uppgick risken till 0,7 procent och även detta värde ligger långt under det europeiska genomsnittet. Tolkningen försvåras dock något av jämförelser med finsk brottsstatistik som redovisar en plötslig ökning av biltillgrepp under slutet av 1990-talet vilken dock inte har hållit i sig.

Enligt olika uppskattningar (EMCDDA, 2002:15) ligger förekomsten av drogmissbruk ("problem drug use") - jämfört med situationen i Väst- och Sydeuropa - nära genomsnittet i Danmark, Norge samt Sverige och under genomsnittet i Finland. En utförlig redovisning av den skandinaviska drogsituationen på 1990talet har gjorts av Olsson m.fl. (1997) och i Östersjöregionerna av Leifman \& Edgren Henricson (2000).

ICVS-projektet undersöker inte enbart omfattningen av utsatthet för brott utan även andra frågor såsom omfattningen av rädsla, vidtagna brottsskyddsåtgärder och attityder mot och erfarenheter av polisen. När det gäller frågor om risker att utsättas för inbrott visar det sig att tillfrågade i Finland, Sverige och Danmark upplever en låg risk jämfört med det europeiska genomsnittet (van Kesteren m.fl., 2000:210). Känslan av otrygghet utomhus i det egna bostadsområde på kvällarna är också låg bland skandinaviska respondenter (ibid., 212; inga uppgifter för Norge). Liknande tendenser visar sig i Europakommissions senaste barometer om den offentliga säkerheten (European Commission, 2003). Som svar på frågan om de tillfrågade hade installerat något slags skydd mot inbrott (som inbrottslarm, speciella lås eller galler för fönster eller dörrar) var det speciellt respondenterna i Finland och Danmark som låg betydligt under genomsnittet (van Kesteren m.fl., 2000:216).

\section{Trender}

Eftersom det saknas offerundersökningar (såväl på nationell som på europeisk nivå) som täcker hela efterkrigstiden, måste beskrivningar av brottstrender baseras på data från polisstatistiken. Trots de kända bristerna med brottsstatistiken är det allmänt accepterat att sådan statistik kan användas för en översiktlig jämförelse av internationella brottstrender.

Antalet brott som rapporteras av polisen har ökat i alla skandinaviska länder 
åtminstone sedan början av 1960-talet. Den minsta ökningen gäller mord och dråp (antalet anmälningar har fördubblats, utom i Finland där nivån tycks vara oförändrad). Den största ökningen gäller antalet rapporterade rån; detta delvis på grund av att denna typ av brott att i slutet av 1950-talet var mer eller mindre okänd. År 1960 registrerades i de fyra skandinaviska länderna totalt 1200 rån. Ökningen därefter kan sannolikt sättas i samband med uppkomsten av en grupp marginaliserade män samt - senare - med tillkomsten av rån bland ungdom. Det är ändå värt att påminna om att rånnivån enligt ICVS i det internationella perspektivet i Skandinavien fortfarande ligger under genomsnittet (jfr. Tabell 1 ovan). När länderna rangordnas på basis av ökningen i fem brottskategorier (mord/dråp, misshandel, våldtäkt, rån och stöld) uppvisar Norge en något större ökning, men generellt är likheterna mellan länderna i Skandinavien när det gäller brottsutvecklingen mer påtagliga än skillnaderna.

Brottstrenderna i de skandinaviska länderna är därutöver i stort lika de som finns i andra västeuropeiska länder. Westfelt (2001) jämförde brottstrender i Skandinavien med brottstrender i Österrike, England \& Wales, Frankrike, (Väst)Tyskland och Nederländerna. Han fann att ökningar förekom i alla länder även om periodvisa lokala skillnader kunde noteras. Figur 1 nedan visar de tydliga likheterna mellan regionerna.

Stabiliseringen av stöldbrottsligheten under 1990-talet kommer även till uttryck i nationella och internationella offerundersökningar. Den tycks alltså vara reell och samtidigt ett internationellt fenomen. Däremot visar offerundersökningar när det gäller våld en annan bild än polisstatistiken: nationell offerstatistik från Danmark, Finland, Holland, Norge och Sverige ger under de gånga 20 åren endast uttryck för smärre förändringar (Westfelt, 2001:76 ff; jfr. Brink \& Sørensen, 2001). Detta kan tolkas på två sätt: dels att brottsstatistikens utveckling har påverkats av ökad anmälningsbenägenhet, dels att brottsstatistiken omfattar våldssegment som inte täcks av traditionella offerundersökningar (som exempelvis våld $i$ skolan, bland utslagna grupper samt viss våld inom nära relationer). 
Figur 1. Brottstrender (polisanmäld misshandel och stöld) i Skandinavien och fem västeuropeiska länder, 1950-2000. Skalanpassade serier, per 100000 invånare. Källa: Westfelt (2001; uppdaterad).

SKAN4 = Danmark, Finland, Norge och Sverige .

EUR5 = Österrike, England \&Wales, Frankrike, (Väst) Tyskland och

Nederländerna.

EUR4 = dito, exkl. Österrike.
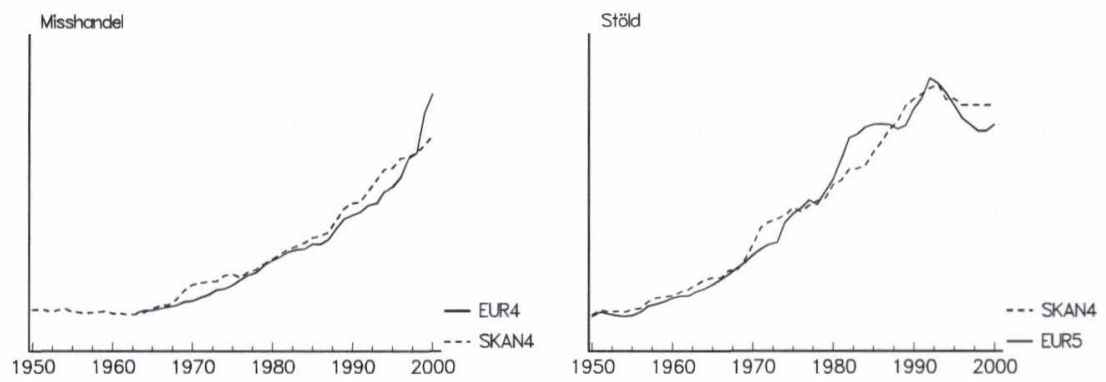

Not. Eftersom serierna ligger på mycket skiftande nivåer, har Y-axeln ritats utan skalangivelse.

Utvecklingen av ungdomsbrottsligheten utgör en speciell fråga. Den har studerats bl.a. av Pfeiffer (1998) och Estrada (1998). Enligt Estrada ökade ungdomsbrottsligheten (dvs. till största delen egendomsbrott) i alla de tio länder som undersöktes (Danmark, Finland, Norge och Sverige, likväl som Österrike, England, (Väst)Tyskland, Nederländerna, Skottland och Schweiz) utan några undantag under årtiondena efter andra världskriget. I flera av dessa länder bröts dock den uppåtgående trenden någon gång i mitten av 1970-talet och tidigt 1980-tal.

Ungdomsvåldet skiljer sig från den generella utvecklingen. Här visar brottsoch lagföringsstatistik i alla länder ökningar under de senaste 10-15 åren (möjligen med undantag av Finland och Skottland). Denna beskrivning har ifrågasatts av Estrada (2001) som hävdar att undersökningar som påvisar sådana ökningar förlitar sig alltför mycket på den officiella brottsstatistiken. Länder där alternativa data finns tillgängliga (dvs. offerundersökningar, självrapporteringsundersökningar, sjukvårdsstatistik med mera) presenterar ofta en annorlunda bild.

Uppfattningen får stöd av självdeklarationsundersökningar som numera regelbundet utförs sedan slutet av 1980-talet bland ungdomar i Danmark och sedan mitten av 1990-talet i Finland och Sverige (Kyvsgaard, 1992; Balvig, 2000; Ring, 2003; Kivivuori, 2002). Bl.a. visar undersökningarna att ungas delaktighet i snatterier, stölder i skolan och skadegörelse har minskat både i Fin- 
land och Sverige, medan delaktighet i våld är mer eller mindre oförändrad. Andelen unga som uppger att de inte deltagit alls i någon form av brott ökar $\mathrm{i}$ såväl Danmark som i Finland och Sverige.

\section{Reaktion på brott}

Antalet poliser per 100000 invånare är lägre i de skandinaviska länderna än i både Syd- och Västeuropa. Under åren 1999-2001 redovisade de skandinaviska länderna totalt 177 poliser per 100000 invånare jämfört med EU-genomsnittet på 345 (Barclay m.fl., 2003:17). Liksom i andra västeuropeiska länder har uppklaringsprocenten sjunkit avsevärt under åren (se Figur 2). Exakt hur denna nedgång skall tolkas är inte klarlagt: exempelvis enbart som en följd av polisens bristande förmåga att klara upp brott och/eller som en följd av att de brott som alltid varit svåruppklarade har ökat (som till exempel mindre allvarliga brott som cykelstölder, vilka polisen dessutom inte prioriterar).

Figur 2. Uppklaringsprocent (samtliga brott) i Skandinavien och fem västeuropeiska länder, 1950-1999. Källa: Westfelt (2001, p. 221; uppdaterad).

EUR5: Österrike, England \& Wales, Frankrike, (Väst)Tyskland och

Nederländerna.

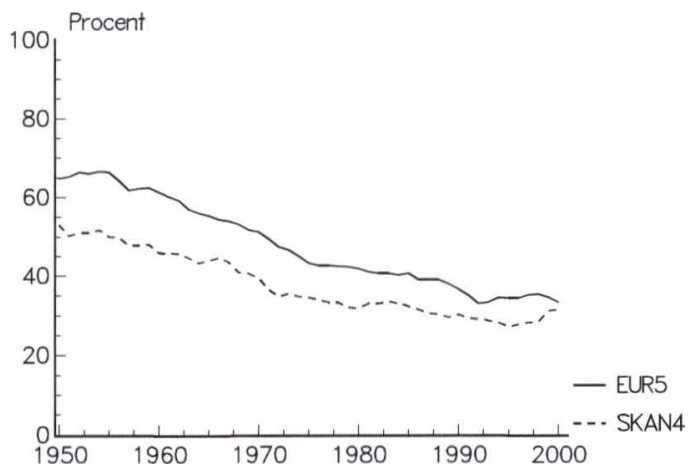

De internationella brottsofferundersökningar (ICVS) visar också att andelen tillfrågade som är nöjda med polisens arbete varierar i Skandinavien (inga data för Norge). Danmark och Sverige toppar listan beträffande frågan i vilken utsträckning personer anmäler brott till polisen (van Kesteren m.fl., 2000:194). När det gäller frågan hur polisen uppträtt direkt vid anmälningstillfället uppvisar Danmark, Finland och Sverige en genomsnittligt högre andel nöjda respondenter (ibid., s. 202). Däremot var de tillfrågade i Sverige genomsnittligt mindre nöjda när det gällde förtroendet för polisen i allmänhet. Förtroendet låg något över genomsnittet i Danmark och Finland (ibid., s. 206). 
ICVS har även undersökt attityder till olika påföljder för brott. Respondenterna gavs möjlighet att välja mellan olika påföljder som de ansåg var mest lämpade för en 21-årig man som befanns skyldig till sitt andra bostadsinbrott, och som denna gång hade stulit en färg-TV. De tillfrågade kunde välja mellan böter, fängelsestraff, samhällstjänst, villkorlig dom eller någon annan påföljd. Sexton procent av de finska respondenterna valde fängelsestraff (van Kesteren m.fl., 2000:219). Motsvarande andel i Norge var 18 procent (år 1989), i Danmark 20 procent och i Sverige 26 procent. Med undantag för Sverige ligger de skandinaviska länderna under det europeiska genomsnittet. Speciellt i de engelskspråkiga länderna och Nederländerna förespråkas ett fängelsestraff $i$ avsevärt högre utsträckning. Det finns vissa antydningar att synen på påföljdsvalet har skärpts något under 1990-talet: i slutet av perioden förespråkar fler ett fängelsestraff än i början av perioden (van Kesteren, a.a.).

\section{Påföljdsval}

Följande korta beskrivning av val av påföljd avser samtliga brott mot strafflagen/brottsbalken sammantaget. En mer detaljerad beskrivning, där olika brottskategorier gås igenom, är inte möjlig i denna korta översikt. ${ }^{3}$ Eftersom majoriteten av brotten mot strafflagen/brottsbalken utgörs av något slags tillgreppsbrott är påföljderna som beskrivs här i praktiken påföljderna för tillgreppsbrott. Uppgifterna avser år 2000. Vad gäller Norge har data delvis skattats eftersom förseelser (t.ex. snatteri) inte ingår i de publicerade standardtabellerna.

Finland lagför fler personer för brott än de andra skandinaviska länderna (1.400 per 100.000 invånara, i jämförelse med 770 i Danmark, 570 i Sverige och 545 i Norge). Finlands position kan delvis förklaras av det legalistiska synsätt som karaktäriserar Finlands rättsväsende med dess relativt strikta användning av obligatoriska åtal (HEUNI, 1995:69). Det har också alltid hävdats från finskt experterhåll, att uppklaringsprocenten de facto är högre i Finland än i övriga Skandinavien.

Samtidigt har Finland, vid jämförelse med andra länder, en mycket hög andel böter (81 procent av samtliga lagföringar); motsvarande andelar i Danmark, Norge och Sverige är 51, 54 respektive 42 procent. "Övriga" påföljder (exkl. fängelsestraff) används mest frekvent i Sverige (44 procent mot 30 i Danmark och 21 i Norge samt 9 procent i Finland). Denna mycket grova skiss fångar troligen ändå ett grundläggande drag när det gäller påföljdsvalet i de skandinaviska länderna. Sverige framstår fortfarande som det land där tanken om individualprevention, baserad på en bred variation av påföljder, är mest märkbar, medan Finland tydligast följer den klassiska traditionen med böter och fängelse som de typiska straffen.

När det gäller fängelsestraff används denna påföljd oftare i Norge och Danmark - både i relativa och absoluta termer - än i Sverige och Finland (fram till 1999). ^̊ andra sidan är fängelsestraffen längre i Finland och Sverige. Denna 
något komplicerade bild visar svårigheterna när man försöker mäta och jämföra påföljdssystemens grad av stränghet i olika länder (Sveri, 1986; Pease, 1994).

\section{Fängelserna ${ }^{4}$}

Oavsett de skillnader som ovan beskrivits, är antalet fångar tämligen lika i Skandinavien. År 2001 var den genomsnittliga fängelsepopulationen i de skandinaviska länderna låg i ett europeiskt perspektiv (63 fångar (inkl. häktade m.fl.) per 1000000 invånare; lägst i Finland med 60 och högst i Danmark med 66). Motsvarande siffra för hela EU var 83 per 100000 invånare (Barclay m.fl., 2003:6). Uppfattningen att fängelsestraffet är skadligt och därför bör undvikas i så stor utsträckning som möjligt, har fortfarande ett visst värde i de skandinaviska länderna (Bondeson, 1998:94) - även om de allra senaste åren kännetecknas av ökande fångtal även i Skandinavien.

I ett europeiskt perspektiv är skandinaviska fängelser relativt små (genomsnittligt mellan 60 och 100 platser), moderna och har en hög personaltäthet. Öppna anstalter, där säkerheten för att förhindra rymningar är låg, står för mellan 20 procent (Sverige) och 34 procent (Danmark) av det totala antalet anstaltsplatser. På grund av detta har de skandinaviska länderna, Finland undantaget, en högre rymningsfrekvens jämfört med andra länder.

Endast mycket få intagna i de skandinaviska fängelserna är under 18 år (denna grupp utgör mindre än en procent av fängelsepopulationen). Andelen kvinnliga fångar uppgår - som i många andra länder - till 5-6 procent, medan andelen utländska medborgare i fängelse varierar ${ }^{5}$ avsevärt - lägst i Finland med 7 procent och högst i Sverige med 27 procent.

Det genomsnittliga fängelsestraffet är kortast i Norge (knappt 3 månader år 2001) mot drygt 7 månader i Finland (notera dock Finlands låga totala fängelsepopulation). ${ }^{6}$ När det gäller antalet personer som avtjänar livstidsstraff' en viss dag år 2001 fanns 16 personer i Danmark, 66 i Finland och 103 i Sverige. Livstidsstraffet är avskaffat i Norge sedan 1981. 
Figur 3. Fängelsepopulationen i Skandinavien och fem västeuropeiska länder, 2001. Per 100000 invånare. Källa: NCS (1997; uppdaterad).

FIN $=$ Finland

SCAN3 $=$ Danmark, Norge och Sverige.

EUR5 = Österrike, England \& Wales, Frankrike, (Väst)Tyskland och Nederländerna.

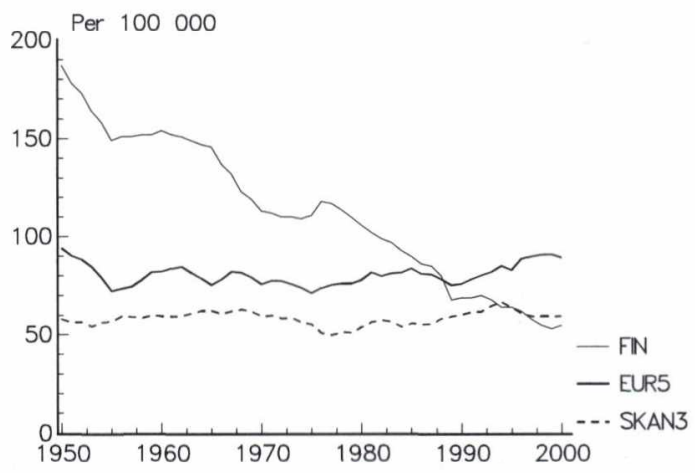

De senaste 40 åren har fängelsepopulationen varit relativt stabil i Danmark, Norge och Sverige (se Figur 3). Finland utgör ett anmärkningsvärt undantag. Där har fängelsepopulationen sjunkit påfallande och är idag något lägre än i de skandinaviska grannländerna; endast Islands fångpopulation ${ }^{8}$ är ännu lägre (39 fångar per 100000 invånare år 2001; CoE, 2002:10). Den politiska processen som ligger bakom nedgången har beskrivits av Törnudd (1993) och Lappi-Seppäla $(1998 ; 2000)$, som bl.a. rätteligen drar slutsatsen att minskningen av fångantalet inte förändrat den finska brottsbilden negativt jämfört med de övriga skandinaviska länderna (ibid. s. 27).

\section{Sammanfattning}

Denna korta översikt över brott och straff i de skandinaviska länderna antyder att brottsnivån i Skandinavien när det gäller den traditionella brottsligheten är på samma nivå eller t.o.m. lägre än i andra jämförbara europeiska länder. Också drogmissbruk förefaller vara utbredd på ett sätt som svarar mot genomsnittet. Ökningen av brottsligheten under efterkrigstiden har varit påtaglig i de skandinaviska länderna liksom i Västeuropa. Ökad jämställdhet mellan könen kan ha bidragit till ökad medvetenhet och större anmälningsbenägenhet vad gäller våldsbrott och sexuella övergrepp mot kvinnor (och barn) och därmed synliggjort dessa brott i växande utsträckning.

Den formella straffrättsliga kontrollen i de skandinaviska länderna karaktäriseras av låg polistäthet, en minskad uppklaringsprocent, användandet av böter 
som påföljd för en stor del av brotten samt en relativt sett låg och stabil (med undantaget Finland) fängelsepopulation.

De internationella brottsofferundersökningarna (inga data för Norge) indikerar att rädsla för brott är jämförelsevis låg i Danmark, Finland och Sverige samt att människor därför inte anser sig i behov av att vidta speciellt omfattande säkerhetsåtgärder för att förebygga brott. De tillfrågade verkar också vara ganska nöjda med polisens insatser och stödjer fortfarande begränsningar av fängelsestraffets användning.

Sammantaget tyder genomgången på att det tycks finnas stora likheter när det gäller utvecklingen av stöld och våld i Skandinavien och andra västeuropeiska länder och att det inte finns någon stark koppling alls mellan brottsutvecklingen å ena sidan och utformningen och dimensioneringen av de straffrättsliga kontrollsystemen eller typ av välfärdsstatsmodell å andra sidan. Politikens möjligheter att direkt kunna styra utvecklingen tycks vara starkt begränsade.

Den bild som tecknats här mot bakgrund av tillgänglig statistik avviker påtagligt från nationella debatter som förs bland politiker och av media. Skälet är att dessa debatter sällan tar sin utgångspunkt $i$ ett jämförande perspektiv. Bestämningsfaktorerna för brottslighet - liksom för andra oönskade samhällsfenomen - diskuteras i stället vanligen i termer av nationell politik och nationella tillkortakommanden (Törnudd, 1995). Samtidigt ges det uttryck för en allmän övertro att kunna "bekämpa" oönskade förhållanden med hjälp av straffrättsliga medel (Jareborg, 1995). Avslutningsvis skall en del likheter beskrivas när det gäller kriminalpolitiska trender i de skandinaviska länderna (se även Lahti, 2000).

\section{Kriminalpolitiska trender}

Under de senaste 25 åren har åtminstone tre brottsgrupper stått i förgrunden för det kriminalpolitiska intresset: vålds- och sexualbrott, narkotikabrott samt delar av den moderna eko- och miljöbrottsligheten. Narkotikabrottsligheten har också varit den enskilt mest betydelsefulla faktorn när det gäller förändringar på fängelserna. Dessutom har våldet i vissa grupperingar (t.ex. mc-gäng), organiserad kriminalitet och brottsligheten bland ungdomar, invandrare och utländska medborgare kommit i fokus för intresset. Till skillnad från situationen på 1970- och början av 1980-talen då det var fråga om systematiska ned- och avkriminaliseringar (exempelvis när det gäller trafikonykterhetsbrott), kännetecknas speciellt 1990-talet av talrika ny- och uppkriminaliseringar. Förändringen tycks ha startat tidigast i Sverige. En del av dessa förändringar har motiverats med behovet att uppfylla ländernas internationella förpliktelser.

I praktiken har individualpreventionen med differentierade påföljdssystem fortfarande ett starkt fotfäste och i alla länder infördes ytterligare alternativ till frihetsstraff. Delvis som ett resultat därav har fängelsepopulationerna - speciellt i ett internationellt perspektiv - hållits relativt konstanta; noteras bör dock att Finland har sänkt sin fångpopulation radikalt. 
Under senare år har också möjligheterna att använda straffprocessuella tvångsmedel och register utökats. Sammantaget tycks de kriminalpolitiska kontrollsystemen röra sig i riktning mot allt större grad av "proaktivitet". Därutöver har betydelsen av det brottsförebyggande arbetet innan- och utanför rättssystemets ramar lyfts fram. Brottsoffrens ställning och rättigheter har utvecklats i alla länder.

Centralt för förståelsen av den kriminalpolitiska utvecklingen under de gångna 25 åren tycks vara att de kriminalpolitiska aktörerna har blivit fler. Tidigare utformades kriminalpolitiken i allt väsentligt av justitiedepartementena i samspel med olika experter. Kriminalpolitiken stod utanför dagspolitiken. Under 1960- och 70-talen kom en första politisering genom klientrörelserna (KRIM, KROM, KRUM) och mediernas växande engagemang. Medan klientrörelserna försvagades eller rent av dog under 1980-talet, etablerade sig - dock i skiftande $\operatorname{grad}^{9}$ - både intresseorganisationer (t.ex. kvinno- och offerrörelser) och borgerliga partier som nya aktörer. Även media markerade i allt större utsträckning ett eget intresse i frågor om brott och straff. Under tidigare decennier skulle justitiedepartementen balansera mellan myndighets- och diffusa medborgerliga intressen (som omfattade både skydd av allmänheten och skydd av lagöverträdaren mot övergrepp). Idag är samma process mycket mer komplicerad: tvåpartsförhållandet har avlösts av ett flerpartsförhållande, där skiftande intressen skall jämkas mellan myndigheter, oppositionella politiska partier, intresseorganisationer och media. Då kriminalpolitiska frågor lyfts upp till den högsta politiska nivån tenderar detta till att sådana lösningsmodeller gynnas som förväntas få positiv genklang hos väljare. Dessa tendenser förefaller fortfarande vara minst utpräglade i Finland.

\footnotetext{
Noter

1) För en nyligen utförd jämförelse av vissa aspekter av modern brottslighet, se van Dijk \& de Waard (2000).

2) Aromaa (2000:19) uttrycker därför farhågor om att Norge under 1990-talet kan ha lämnat sin position som lågbrottsland.

3) Se dock European Sourcebook (2003).

4) Data i detta avsnitt har hämtas från CoE (1999a; 1999b; 2002) och NSt (2003).

5) I förhållande till olikheterna i storlek på den utländska populationen; se ovan.

${ }^{6}$ Uppgifterna är beräknade utifrån tab. 1A, 1B, 2A och 2B i NSt (2003).

7) Om livstidsstraffet i Norden, se Träskman (2001).

8) Om fängelserna på Island, se Baldursson (2000).

9) Offerrörelsen är exempelvis svag i Danmark.
} 


\section{Litteratur}

Aromaa, K., Trends in Criminality. I: Crime and Criminal Justice in Europe, s. 13-34. Strasbourg: Council of Europe Publishing, 2000.

Baldursson, E., Prisoners, Prisons and Punishment in Small Societies, Journal of Scandinavian Studies in Criminology and Crime Prevention, Årg. 1(1), s. 5-15, 2000.

Balvig, F., RisikoUngdom. København: Det Kriminalpræventive Råd, 2000.

Barclay, G., Tavares, C. \& Wilby, E. International comparisons of criminal justice statistics 2001. London: Home Office, 2003. Under publicering.

Brink, O. \& Sørensen, V., Er voldens mørketal faldende? Nordisk Tidsskrift for Kriminalvidenskab, Årg. 88, s. 230-239, 2001.

Bondeson, U., Global Trends in Corrections, Annales Internationales de Criminologie, Årg. 36(1/2), s. 91-116, 1998.

CoE, Council of Europe Annual Penal Statistics SPACE I. Survey 1997. PC-CP (99) 3 REV. Strasbourg, 5 July 1999a.

CoE, European Sourcebook of Crime and Criminal Justice Statistics. PC-S-ST (99) 8 REV. Strasbourg, 7 July 1999b.

CoE, SPACE I. Annual Penal Statistics of the Council of Europe. 2001 Enquiry. PC-CP (2002) 1 rev. Strasbourg, 12 June 2002.

van Dijk, F. \& de Waard, J., Legal infrastructure of The Netherlands in international perspective. Crime control. [The Hague:] Ministry of Justice The Netherlands.

EMCDDA, Annual Report on the State of the Drugs Problem in the European Union 2002. European Monitoring Centre for Drugs and Drug Addiction. Luxembourg: Office for Official Publications of the European Communities, 2002.

European Commission, Results of Eurobarometer 58.0 (Autumn 2002). Analysis of Public Attitudes to Insecurity, Fear of Crime and Crime Prevention. DG PRESS B/1/UTM D(2003). Brussels, 25 April 2003. [http://europa.eu.int/comm/justice_home/eucpn/projects.html]

European Sourcebook, European Sourcebook of Crime and Criminal Justice Statistics 1995-2000, 2003. Under publicering.

Estrada. F., Juvenile Crime Trends in Post-War Europe, European Journal on Criminal Policy and Research, Årg. 7, s. 23-42, 1999.

Estrada, F., Juvenile violence as a social problem, British Journal of Criminology, Årg. 41, s. 639$655,2001$.

HEUNI, Profiles of Criminal Justice Systems in Europe and North America. K. Kangaspunta (red.), European Institute for Crime Prevention and Control, affiliated with the United Nations. Publication Series No. 26. Helsinki, 1995.

HEUNI, Profiles of Criminal Justice Systems in Europe and North America 1990-1994. K. Kangaspunta, M. Joutsen, N. Ollus and S. Nevala (red.), European Institute for Crime Prevention and Control, affiliated with the United Nations. Publication Series No. 33. Helsinki, 1998.

Jareborg, N., Vilken sorts straffrätt vill vi ha? I: D. Victor (red.), Varning för straff. Om vådan av den nyttiga straffrätten, s. 19-37. Stockholm: Norstedts, 1995.

van Kesteren, J., Mayhew, P. And Nieuwbeerta, P., Criminal Victimisation in Seventeen Industrialised Countries. Key findings from the 2000 International Crime Victims Survey. Onderzoek en beleid 187. The Hague: WODC, 2000.

Kivivuouri, J. (red.), Summary. Trends and patterns of self-reported juvenile delinquency in Finland. Publication No. 188, s. 159-166. Helsinki: National Research Institute of Legal Policy, 2002.

Kyvsgaard, B., Ny ungdom? København: Jurist- og Økonomforbundets Forlag, 1992.

Lahti, R., Om den nordiska kriminalpolitikens utveckling, Nordisk Tidsskrift for Kriminalvidenskab, Årg. 87, s. 177-192, 2000.

Lappi-Seppälä, T., Regulating the Prison Population. Experiences from a Long-Term Policy in Finland. National Research Institute of Legal Policy. Research Communications 38. Helsinki, 1998. 
Lappi-Seppälä, T., The Fall of the Finnish Prison Population, Journal of Scandinavian Studies in Criminology and Crime Prevention, Årg. 1(1), s. 27-40, 2000.

Lappi-Seppälä, T. (red.), Homicide in Finland - Trends and patterns in historical and comparative perspective. Publication No. 181. Helsinki: National Research Institute of Legal Policy, 2001.

Leifman, H. \& Edgren Henrichson, N. (red.), Statistics on Alcohol, Drugs and Crime in the Baltic Sea Region. NAD Publication No. 37. Helsinki: Nordic Council for Alcohol and Drug Research, 2000.

NSt, Nordisk statistik för kriminalvården i Danmark, Finland, Norge och Sverige 1997-2001. Norrköping: Kriminalvårdsstyrelsen, 2002.

Olsson, B. m.fl., The Nordic drug scene in the 1990s: recent trends, Nordic Studies on Alcohol and Drugs, Årg. 14 (English Supplement), 1997.

Pease, K., Cross-National Imprisonment Rates. Limitations of Method and Possible Conclusions, British Journal of Criminology, Årg. 34, s. 116-130.

Pfeiffer, C., Juvenile crime and violence in Europe. I: M. Tonry (red.), Crime and Justice: A Review of Research, Årg. 23, s. 255-328. Chicago, IL: University of Chicago Press, 1998.

Ring, J., Stöld, våld och droger bland ungdomar $i$ årskurs nio. Resultat från fyra självdeklarationsundersökningar. Rapport 2003:5. Stockholm: Brottsförebyggande rådet, 2003.

RSA, Nordisk kriminalstatistik. I: Rättsstatistisk årsbok 1990. Sveriges Officiella Statistik. Stockholm: Statistiska centralbyrån, s. 142-152, 1990.

Sveri, K., Om användning av straffrättsliga påföljder i Norden, Västtyskland och England. I: SOU 1986:15, Påföljd för brott. Huvudbetänkande av fängelsestraffkommittén. 3 Bilagor. Bilaga 3, s. 55-91. Stockholm: Justitiedepartementet, 1986.

Träskman, P.O. m.fl., Tio år med straffvärdet, Nordisk Tidsskrift for Kriminalvidenskab, Årg. 87, s. 136-153, 2000.

Träskman, P.O., Utestängning genom tidsobestämd inspärrning - det problematiska livstidsstraffet. I: Vagn Greve, Beth Grothe Nielsen \& Annika Snare (red.), Nytter det? Mosaik om kriminalforsorg og kriminalpolitik. Tilegnet Ole Ingstrup. København: Jurist- og Økonomforbundets Forlag, s. 151-169, 2001.

Törnudd, P., Fifteen Years of Decreasing Prisoner Rates in Finland. National Research Institute of Legal Policy. Research Communication 8. Helsinki, 1993.

Törnudd, P., Setting Realistic Policy Goals, Scandinavian Studies in Criminology, Årg. 14, s. 37-50, 1995.

Vogel, J., Living conditions and inequality in the European Union 1997. Eurostat Working Papers. Population and social conditions. E/1997-3. [Working document]. 1997.

Westfelt, L. Brott och straff $i$ Sverige och Europa. En studie $i$ komparativ kriminologi. Kriminologiska institutionen. Avhandlingsserie Nr 5. Stockholm: Stockholms universitet, 2001.

\author{
Adresse: Kriminologiska institutionen \\ Stockholms universitet \\ S - 10691 Stockholm \\ e-post: Hanns.Hofer@crim.su.se
}

